\title{
Effect of cardiac 'nondisease' on intellectual and perceptual motor development
}

\author{
Glen G. Cayler, David B. Lynn, and Edwina M. Stein \\ From The Sutter Hospitals Medical Research Foundation, Sacramento, California; and \\ The Department of Applied Behavioral Sciences, University of California, Davis, California, U.S.A.
}

The relation between the misdiagnosis of heart disease (cardiac 'nondisease') and intellectual and perceptual motor development was investigated by comparing the performance on the WISC and the Bender-Gestalt tests of 9 restricted and 25 nonrestricted children with cardiac 'nondisease' with 31 children of comparable age and racial and socioeconomic backgrounds. On the WISC, the restricted children had the lowest full-scale verbal and performance scores and showed the most variability between their verbal subtest scores. The nonrestricted children had lower full scale and verbal scores and showed more variability in their verbal subtest scores than did the control children. The functioning of all three groups on the Bender-Gestalt test did not differ significantly; and it is, therefore, unlikely that the impaired performance on the WISC of the children with cardiac 'nondisease' was due to organic brain disease. It is concluded that the accumulative emotional factors of the diagnosis of heart disease, especially if accompanied by physical restrictions, are detrimental to intellectual development. Family physicians, paediatricians, and paediatric cardiologists are consequently urged to do more complete and earlier evaluations of the cardiac status of infants and small children who are suspected to have heart disease in order to minimize the number who are falsely diagnosed. Additionally, exercise restrictions should be advised only for children with proved cardiac lesions which were moderate to severe.

Because functional or innocent heart murmurs are frequent in children and because these murmurs are often misdiagnosed to be due to cardiac defects, many infants and children are incorrectly considered to have heart disease (Cayler and Warren, 1970; Bergman and Stamm, 1967; Coleman and Doig, 1970; Landtman, Valanne, and Aukee, 1968). Not infrequently children with cardiac 'nondisease' are restricted from normal physical activities at home and in school (Cayler and Warren, 1970; Bergman and Stamm, 1967). The present study investigated the effect of a false diagnosis of heart disease on intellectual and perceptual motor performance. The Wechsler Intelligence Scale for Children (WISC) was used to measure intellectual function and the Bender-Gestalt to measure perceptual motor performance. Based on previously reported data concerning the intellectual and perceptual motor development of normal children (Kagan and Moss, 1959; Winterbottom, 1958) and of children with heart disease (Chazan et al., I95I ; Glaser, Harrison, and Lynn, I964; Apley, Barbour, and Westmacott,

Received II May 1972.
1967; Scarth and Kay, 1969), it was thought that children misdiagnosed to have heart disease would suffer a loss of intellectual and perceptual motor function from the emotional stress of the diagnosis and of the imposed restrictions.

\section{Subjects and methods}

A sample of 34 children erroneously diagnosed as having heart disease was selected in sequential order from the files of one of the authors (G.G.C.). The children, constituting a varied racial and socioeconomic group, were referrals for evaluation from either private physicians or public agencies. The children had been subjected to the emotional stress accompanying the diagnosis of heart disease for periods of 3 to ro years (Table I). All but 12 per cent of the children had been labelled to have heart disease by the age of 5, 44 per cent having been labelled during infancy. The sample consisted of two groups (Table I): Group A (9 children), misdiagnosed children with imposed physical activity restrictions, was composed of 6 white boys and I black boy, ranging in age from 9 to II years, and 2 white girls, ages ro and II years. Of this group, one boy had been assigned to a remedial reading class and I girl received methyl phenidate for control of hyperactivity in school. Group B (25 
TABLE I Children studied

\begin{tabular}{|c|c|c|c|c|}
\hline & No. & $M / F$ & $\begin{array}{l}\text { Mean age } \\
\text { (age range }\end{array}$ & $\begin{array}{l}\text { Mean years } \\
\text { of incorrect } \\
\text { diagnosis }\end{array}$ \\
\hline $\begin{array}{l}\text { Group A } \\
\text { (restricted) }\end{array}$ & 9 & $7 / 2$ & $\begin{array}{l}\text { IO yr } 5 \mathrm{mth} \\
(9-\mathrm{II})\end{array}$ & \\
\hline $\begin{array}{l}\text { Group B } \\
\text { (nonrestricted) }\end{array}$ & 25 & $14 /$ I I & $\begin{array}{l}9 \text { yr } 3 \mathrm{mth} \\
(7-\mathrm{II})\end{array}$ & $7 \mathrm{yr} 6 \mathrm{mth}$ \\
\hline $\begin{array}{l}\text { Group C } \\
\text { (control) }\end{array}$ & 31 & $19 / 12$ & $\begin{array}{l}\text { Io yr Io mth } \\
(7-\mathrm{II})\end{array}$ & \\
\hline
\end{tabular}

children), misdiagnosed children without physical activity restrictions, consisted of 13 white boys and I black boy, ranging in age from 7 to II years, and Io white girls and I black girl, ranging in age from 8 to I I years. In this group 5 children, 3 boys and 2 girls, had scholastic achievement problems and 2 boys received methyl phenidate for school behavioural problems. All children in Groups A and B resided within 24 miles of Sacramento and, with the exception of $I$ child who was adopted during infancy, lived with one or both natural parents.

A sample of 31 normal children was selected from three Sacramento elementary schools. These schools had been judged by the Chairman of Planning and Research for the Sacramento Unified School District to be comparable to the heart sample in their socioeconomic level and racial distribution. The sample was selected from an initial pool of 180 children in the following manner: the pool was composed by drawing from the school medical records the names of boys and girls who lived with one or both natural parents and who corresponded in age and sex to the erroneously diagnosed cardiac children. When possible only children with a negative phonocardioscan examination (Cayler and Warren, 1970) were selected. Children were randomly chosen from the pool and the parent of each child was sent a medical history questionnaire to ensure that no child with rheumatic fever, heart disease, or potential neurological impairment was selected. Failure of $7 \mathrm{I}$ per cent of the parents to respond to the questionnaire and half of the parents to respond to telephone contact substantially reduced the potential size of the pool.

The WISC, a particularly sensitive scale, was selected in the present study as a measure of intellectual function because of the many possibilities of variability within the subtest scores. Discrepancies among subtests and verbal and performance IQ's have been used as indices of brain damage (Heilbrun, 1959; Reitan, r958) and also psychological disturbances (Trehub and Scherer, 1958). The Bender-Gestalt was used to measure perceptual motor function. Discrepancies such as change in curvature rotation, lack of orderliness, and lack of coherence of figures have been used as indices of organic brain damage (M. P. Honzik, 1969, Bender-Gestalt performance of heart children, personal communication; Oki et al., 1960) and personality disturbances in children (Byrd, 1956; Fuller, 1963).

Both groups of misdiagnosed children were individu- ally tested on their appointment date in the physician's conference room at the Sutter Memorial Hospital. The normal children were individually tested in the space provided by the principal of the school. All of the children were tested by one of the authors (E.M.S.). Each child was first given the Bender-Gestalt and then the WISC in the manner prescribed by the manuals accompanying each test.

Analysis of variance, corrected for unequal numbers, was used to compare the WISC scores and the $\chi^{2}$ test was used to compare the Bender-Gestalt scores.

\section{Results}

The mean WISC full scale IQ score for the misdiagnosed restricted children was 97 , III for the misdiagnosed nonrestricted children, and II 4 for the control group. The analysis of variance shows that the values for the groups differed significantly (Table 2). Fig. I shows that the difference between Group B (nonrestricted) and the controls is due to the difference in verbal IQ, as the mean performance scores are almost identical.

TABLE 2 Analysis of variance for full scale WISC $I Q$ 's for restricted, nonrestricted, and control groups

\begin{tabular}{lrrl}
\hline Source & d.f. & \multicolumn{1}{l}{$M S$} & $F$ \\
\hline Between subjects & 64 & & \\
$\quad$ Groups (A) & 2 & $954 \cdot 83$ & $3 \cdot 52^{\star}$ \\
Error (S/A) & & $271 \cdot 38$ & \\
Within subjects & 65 & & \\
Subtests (B) & I & $463 \cdot 39$ & $4.90 \dagger$ \\
A $\times$ B & 2 & $140 \cdot 98$ & $1 \cdot 71$ \\
Error (SB/A) & $\mathbf{6 2}$ & $\mathbf{8 2} \cdot 36$ &
\end{tabular}

$\star \mathrm{P}<0.05$. d.f. $=$ degrees of freedom; $M S=$ mean squares. $+P<0.025$. $F=$ ratio of mean squares.

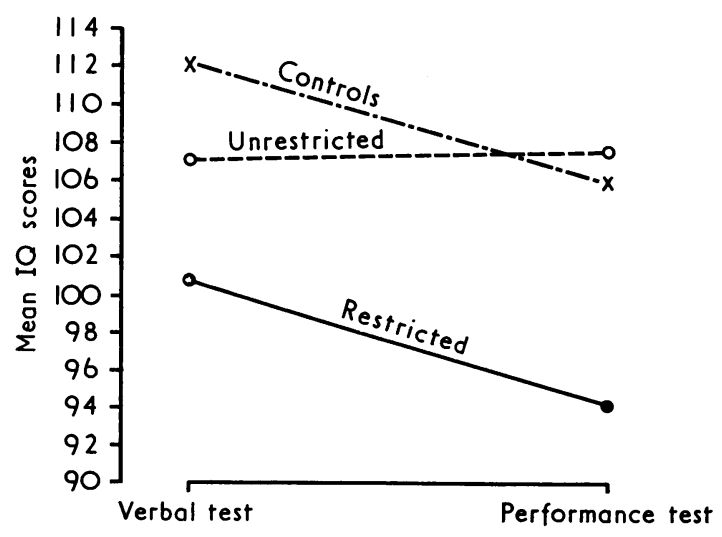

FI I. I Mean verbal performance IQ scores on WISC for the restricted, nonstricted, and control groups. 
TABLE 3 Frequency of subjects with higher verbal than performance $I Q$, higher performance than verbal $I Q$, and equal verbal and performance IQ's for restricted, nonrestricted, and control groups

\begin{tabular}{lcccl}
\hline Group & No. & $V>P$ & $P>V$ & $P=V$ \\
\hline Restricted & 9 & 6 & 3 & 0 \\
Nonrestricted & 25 & 13 & 10 & 2 \\
Control & 31 & 17 & II & 3
\end{tabular}

Note: V, verbal scale IQ; P, performance scale IQ.

Table 3 shows that in all three groups there are more subjects whose verbal score surpassed the performance value than there are subjects with the performance score surpassing the verbal score. None of the subjects of the misdiagnosed restricted group, only 2 subjects in the misdiagnosed nonrestricted group, and 3 subjects in the control group show equal verbal and performance scores.

The analysis of variance of the verbal scale scores (Table 4) indicates a significant difference in subtest variability among the groups. The interaction value of 2.6I strongly suggests that the three groups of children did not show parallel functioning. The degree of variability among verbal subtests for each group (Fig. 2) shows the subjects of the restricted children to be the most variable with means ranging from 6.33 to 10.22 ; the subjects of the nonrestricted children are intermediate with means ranging from $7 \cdot 20$ to 10.76; and the control children showed the
TABLE 4 Analysis of variance for verbal scale $I Q$ and verbal subtests for restricted, nonrestricted, and control groups

\begin{tabular}{lrll}
\hline Source & d.f. & MS & \multicolumn{1}{l}{$F$} \\
\hline Between subjects & 64 & & \\
Groups (A) & 2 & 11.67 & 0.58 \\
Error (S/A) & 62 & 20.16 & \\
Within subjects & 325 & & \\
Subtests (B) & 5 & 83.97 & $12.57 \dagger$ \\
A $\times$ B & 10 & 17.44 & $2.61^{\star}$ \\
Error (SB/A) & 310 & 6.68 &
\end{tabular}

Note: In the between subjects analysis the sum of the weighted verbal subtests scores was used which can be directly converted by table into the verbal scale IQ.

$\star \mathrm{P}<0.025$.

$+\mathrm{P}<0.001$.

least variability with means ranging from $8.8 \mathrm{I}$ to 10.84. The subjects performance of the restricted children was the lowest on all subscales except comprehension and was particularly low on vocabulary (Fig. 2). With the exception of the picture completion subtest, the mean subjects performance score of the restricted children is the lowest of the three groups (Fig. 3); however, the nonrestricted and control children showed the greatest range of variation between the performance subscores. The restricted children had an unusually low mean score of 8.0 on the coding subtest. The analysis of variance of the performance subtest scores shows a 2.14 calculated value of interaction which is not signifi-

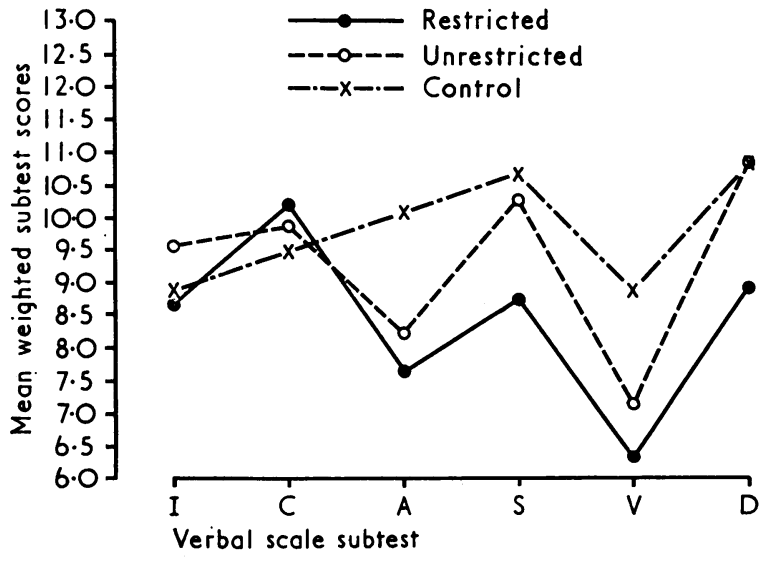

FIG. 2 Mean weighted subtest scores on the verbal scale of the WISC for the restricted, nonrestricted, and control groups. I, information; $C$, comprehension; $A$, arithmetic; $S$, similarities; $V$, vocabulary; $D$, digit span. 
TABLE 5 Analysis of variance for performance scale $I Q$ and performance subtests for restricted, nonrestricted, and control groups

\begin{tabular}{lrll}
\hline Source & d.f. & \multicolumn{1}{l}{$M S$} & $F$ \\
\hline Between subjects & 64 & & \\
Groups (A) & 2 & 64.71 & $12 \cdot 71^{\star}$ \\
Error (S/A) & 62 & 5.09 & \\
Within subjects & 260 & & \\
Subtests (B) & 4 & 23.68 & 2.36 \\
A $\times$ B & 8 & 21.52 & $2 \cdot 14$ \\
Error (SB/A) & 248 & 10.04 & \\
\hline
\end{tabular}

Note: In the between subjects analysis the sum of the weighted performance subtests scores was used which can be directly converted by table into the performance scale IQ. $\star \mathrm{P}<0.00 \mathrm{r}$.

TABLE 6 Frequencies and expected frequencies for errors on Bender-Gestalt for restricted, nonrestricted and control groups

\begin{tabular}{lcc}
\hline Group & $\begin{array}{l}\text { Normal or } \\
\text { fewer errors }\end{array}$ & $\begin{array}{l}\text { More than } \\
\text { normal errors }\end{array}$ \\
\hline Restricted & $5(5.68)^{\star}$ & $4(3.32)$ \\
Nonrestricted & $16(15 \cdot 77)$ & $9(9 \cdot 23)$ \\
Control & $20(19.55)$ & $11(11 \cdot 95)$ \\
\hline
\end{tabular}

$\star$ Numbers in parentheses refer to expected frequency.

cant and contrasts with the significant difference in verbal function (Table 5).

The $\chi^{2}$ test (Table 6) fails to show significant effects of diagnosis and imposed physical restriction on the Bender-Gestalt test $\left(\chi^{2}=2.59 ; d=2 ; \mathrm{p}\right.$, not significant).

\section{Discussion}

The impaired performance of the children with cardiac 'nondisease' on the WISC test probably cannot be ascribed to brain damage or neurological differences between the groups since the performance of all three groups was not significantly different on the Bender-Gestalt test, the latter test being a sensitive measure of brain damage (M. P. Honzik, 1969, personal communication; Oki et al., 1960). It is of interest that Honzik ( 1969 , personal communication) reported lower performance on the BenderGestalt test for children with heart disease compared to normal children, suggesting that children with heart disease are doubly impaired by both environmental and organic factors.

Since the WISC scores of the restricted children in our study are lower than both the nonrestricted and the control children, it can be concluded that the imposed restrictions rather than the diagnosis of heart disease itself have the greater effect on intellectual development. This conclusion is consistent with the findings of Kagan and Moss (1959) who reported a positive relation between mothers' encouragement and their children's early developmental progress and the amount of increase in measured IQ which the children subsequently showed between the ages of 6 and ro years.

It is unlikely that the unusual verbal subtest pattern of the restricted children is due to the predominance of males in this group (Table $I$ ), since Honzik et al. (1969) had previously reported lower vocabulary, information, and arithmetic scores for girls than for boys. It would therefore be expected that the increased percentage of males in our restricted group would lessen rather than accentuate the difference between their comparative performances.

Linde, Rasof, and Dunn (1967) reported that young cardiac children whose activities were restricted had lower full scale IQ scores and noted a tendency for the lower scores of younger children to rise with age. Our study shows the full scale IQ of older misdiagnosed restricted children to be lower than normal controls. The disagreement between our findings and those of Linde et al. may possibly be due to a difference in the test instruments, as they used the Stanford-Binet test, which primarily measures verbal abstractions, while we used the WISC which measures both verbal and performance functioning. Additionally, the study of Linde et al. did not include normal controls.

\section{References}

Apley, J., Barbour, R. F., and Westmacott, I. (1967). Impact of congenital heart disease on the family: preliminary report. British Medical fournal, I, 103.

Bergman, A. B., and Stamm, S. J. (1967). The morbidity of cardiac nondisease in schoolchildren. New England fournal of Medicine, 276, 1008.

Byrd, E. (1956). The clinical validity of the Bender-Gastalt test with children: a developmental comparison of children in need of psychotherapy and children judged welladjusted. Fournal of Protective Techniques, 20, 127.

Cayler, G. G., and Warren, M. C. (1970). Benefits from mass evaluation of school children for heart disease (experience with 6,625 children). Chest, 58, 349.

Chazan, M., Harris, T., O’Neill, D., and Campbell, M. (I95I). The intellectual and emotional development of children with congenital heart disease. Guy's Hospital Reports, 100, 331.

Coleman, E. N., and Doig, W. B. (1970). Diagnostic problems with innocent murmurs in children. Lancet, 2, 228.

Fuller, G. B. (1963). A further study on rotation; cross-validation. Fournal of Clinical Psychology, 19, 127.

Glaser, H. H., Harrison, G. S., and Lynn, D. B. (1964). Emotional implications of congenital heart disease in children. Pediatrics, 33, 367.

Heilbrun, A. B. (1959). Lateralization of cerebral lesion and performance on spatial-temporal tasks. Archives of Neurology, $\mathbf{1}, 282$. 
Honzik, M. P., Collart, D. S., Robinson, S. J., Finley, K. H. (1969). Sex differences in verbal and performance I.Q.'s of children undergoing open-heart surgery. Science, 164, 445.

Kagan, J., and Moss, H. A. (1959). Parental correlates of child's I.Q. and height: a cross-validation of the Berkeley growth study results. Child Development, 30, 325 .

Landtman, B., Valanne, E. H., and Aukee, M. (1968). Emotional implications of heart disease, a study of 256 children with real and with imaginary heart disease. Annales Paediatriae Fenniae, 14, 71.

Linde, L. M., Rasof, B., and Dunn, O. J. (1967). Mental development in congenital heart disease. Fournal of Pediatrics, 71, 198.

Oki, T., Sakai, T., Kizu, M., and Higashi, H. (1960). A comparative study concerning the psychological traits of children with organic brain damage and subnormal oligophrenia. Fapanese Fournal of Child Psychiatry, 1, 126.
Reitan, R. M. (1958). Qualitative versus quantitative mental changes following brain damage. Fournal of Psychology, 46, 339.

Scarth, L. G., and Kay, D. W. K. (1969). Protracted cardiac neurosis with congenital heart disease in one of identical twins. British Heart fournal, 31, 404.

Trehub, A., and Scherer, I. W. (1958). Wechsler-Bellevue scatter as an index of schizophrenia. Fournal of Consulting and Clinical Psychology, 22, 147.

Winterbottom, M. R. (1958). The Relation of Need for Achievement to Learning Experience and Independence and Mastery. Motives in Fantasy, Action, and Society. Nostrand, Princeton, N.J.

Requests for reprints to Dr. Glen G. Cayler, 52nd and F Street, Sacramento, California 95819, U.S.A. 